\title{
George Inzelt: a tribute on the occasion of his 70th birthday
}

\author{
Gyözö G. Láng ${ }^{1}$
}

Received: 26 September 2016 / Accepted: 28 September 2016

(C) Springer-Verlag Berlin Heidelberg 2016

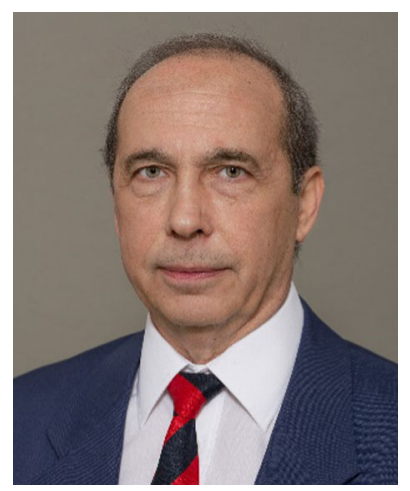

"The main purpose of science is simplicity and as we understand more things, everything is becoming simpler." (Edward Teller).

This Festschrift issue of the Journal of Solid State Electrochemistry is presented in honor of Professor George (György) Inzelt, on the occasion of his 70th birthday on November 2, 2016. It contains contributions covering a wide range of topics in the areas of electrochemistry, electroanalytical chemistry, electronics, instrumentation, data acquisition, modeling, and chemical engineering, reflecting the many areas where George's work had a great impact. The above quote by the famous Hungarian-American theoretical physicist Edward Teller is a good motto for a scientist performing research at the highest international level and who is, at the

Gyözö G. Láng

langgyg@chem.elte.hu; langgyg@ caesar.elte.hu

1 Institute of Chemistry, Department of Physical Chemistry, Eötvös Loránd University, Pázmány P. s. 1/A, Budapest H-1117, Hungary

same time, an excellent academic teacher. George's exemplary career, his discoveries, and his excellent books and papers are a continuous source of knowledge and inspiration for generations of researchers and students. Furthermore, it is also representative of George's general strategy for dealing with scientific problems.

Professor Inzelt is a worldwide recognized specialist in the field of conducting polymer films and other modified electrodes but he also has made pioneering contributions in many fields, including electroanalysis, sensors, surface electrochemistry, electrocatalysis, radiotracer methods, nanoelectrochemistry, transport processes, kinetics and mechanism, theory and simulation, spectroelectrochemistry, etc. He is a very well-known and highly respected member of the electrochemical community. Since it is not easy to summarize his invaluable contribution to electrochemistry, we only highlight a few aspects of his professional life.

George Inzelt was born in Budapest, Hungary, on November 2. He studied at Eötvös Loránd University in Budapest where he obtained his diploma in chemistry in 1970, and earned his $\mathrm{PhD}$ from the same university in 1972. An exceptional student, he was able to complete his doctoral dissertation and all other requirements for his doctoral degree in 2 years' time, an academic achievement extremely rare in the typically difficult and demanding Hungarian university system. In 1978, he received the CSc degree from the Hungarian Academy of Sciences. His supervisors were Prof. Tibor Erdey-Grúz (who was one of the founders of the kinetics of electrode processes) and Prof. György Horányi (who was an internationally recognized expert in radiotracer techniques and interfacial thermodynamics). In that time, he has worked on various topics of physical chemistry and electrochemistry, including the electrochemistry of organic compounds, adsorption processes in electrochemical systems, polymer-gel structures, hydration of polymers, electrochemical oscillations, and 
the determination of self-diffusion coefficients in solvent mixtures. Since the early 80th of the twentieth century, George published numerous papers on electrodes modified by electroactive polymer films. His first study in this area dealt with electrodes modified by tetracyanoquinodimethane, which was started when George was working in 1982-1983 with James Q. Chambers at the University of Tennessee. Back in Hungary, he continued this research and expanded it into various directions, working with several electrochemically active polymers. He received his Doctor of Science degree (DSc) in 1988 from the Hungarian Academy of Sciences. In 1990, he was appointed as a full professor in the Department of Physical Chemistry at the Eötvös Loránd University.

Not only was he to continue his first-class research and establish a new research school, but in keeping with his senior position at the university he became inevitably more involved with science administration. George has served two terms as national secretary (1993-1998) and three terms (1996-2003) as co-chairperson of Division 2 ("Electronically and Ionically Conducting Phases") of the International Society of Electrochemistry (ISE). He was elected for the position of chairperson of Division 1 in 2005, and from 2007, he served as the chair (chair-elect, past chair) of Division 1 (Analytical electrochemistry). He has been a member of the Tajima Prize, Oronzio De Nora Prize, and ISE Fellow Nominating Committees. He was the chairman of the 47th Annual Meeting of ISE that was held in Balatonfüred, Hungary, in 1996, and he was member of the Scientific Committees of several ISE and ISE sponsored meetings in the last three decades. George Inzelt has been elected as ISE fellow in 2009. He has been an IUPAC fellow since 2000, and member of the Advisory Board of Division 1. He was the chairman of the Electrochemistry Commission of the Hungarian Academy of Sciences (1994-2006), served as the Vice Rector for Education and Research (1994-1997) and was the head of the Institute of Chemistry at the Eötvös Loránd University (1999-2006). In addition, he has been a member of the Editorial Board of Electrochimica Acta (1997-2002, 20052007), Electrochemistry Communications (since 1999), and Journal of Solid State Electrochemistry (since 1998,
Regional Editor (Europe) since 2003, Topical Editor since 2007). He has been Topical Editor for the Journal ChemTexts for the area Physical Chemistry since the start of the journal in 2015. Professor Inzelt received a Doctor Honoris Causa title from the Babes-Bolyai University, Cluj, Romania, in 2000. In 2004, he was awarded the Polanyi Medal from the Hungarian Academy of Sciences for his results in the field of physical chemistry, and in 2011, he received the prestigious Széchenyi Prize, the highest honor in Hungary for scientific achievements.

He has published over 300 research papers, several reviews and book chapters, and he has received more than 4000 independent citations on his works. He also has published numerous articles in journals aimed at popularizing chemistry. His deep interest in the history of science, especially as it concerns electrochemistry, is well known. He has published several papers, chapters, and books also in that field. He has contributed to very important chapters in a number of books, including the Encyclopedia of Electrochemistry (Wiley-VCH), the Electrochemical Dictionary (Springer), and the textbook Electroanalytical Methods (Springer). His book Conducting Polymers-A New Era in Electrochemistry (Springer) "is a comprehensive reference guide for those interested in this field". The second edition of this extremely popular book appeared in 2012.

Throughout his career, George has always attracted students to write dissertations with him, doubtless the best certificate of an excellent academic teacher and a successful researcher. The culture of the Inzelt Group has always been one of hard work and attention to detail, aiming to always produce the highest quality research.

At his 70th birthday, his colleagues and friends, and in particular those who have contributed to this special issue of Journal of Solid State electrochemistry, thank George Inzelt for his commitment to science, for his leadership in electrochemical research, and his advocacy of the importance of science education to the intellectual and economic health of society.

We wish him happiness on his birthday and good health and energy in the future: Ad multos annos! 